\title{
Ayurveda Medicinal Management of Encysted hydrocele in a Child (A Case Study)
}

\author{
Vyas P. P. ", Singhal H. K. \\ Deptt of Kaumarbhritya (Pediatrics), Dr S R Rajasthan Ayurveda University, Jodhpur \\ *Corresponding Author: drppvyas@gmail.com
}

Copyright (C) 2014 Horizon Research Publishing All rights reserved.

\begin{abstract}
Encysted hydrocele is a condition usually affecting children. A case of encysted hydrocele of right cord in 3 year old male child was reported. The diagnosis was made Encysted hydrocele on the basis of signs \& symptoms and Ultra sonography. . The patient was suggested for the surgery, by the eminent pediatricians. Surgery was not preferred by parents of the patient. The patient has shown interest to follow, Ayurveda treatment, willingly. An Ayurveda medicinal management was done and found effective in the case of Encysted Hydrocele with abnormally enlarged scrotum. Patient was advised to follow the Ayurveda management for 1 month. Follow up report has shown encourageous result. The size of right testicle was significantly reduced and returned to almost normal size.
\end{abstract}

Keywords Encysted Hydrocele, USG, Rt, Ayurveda

\section{Introduction}

Hydrocele is a scrotal collection of clear fluid ("hydro" water) in a thin walled sac ("cele" -swelling) that also contains the testicle. An encysted hydrocele or a non-communicating type of inguinal hydrocele, is a loculated fluid collection along the spermatic cord, separated from and located above the testicle and the epididymis, as a result of aberrant closure of the processus vaginalis. This is idiopathic in most cases but in some cases it may be emerged secondary to testicular torsion, tumour or trauma, and in infections, as can be seen in, orchitis, epididymitis, tuberculosis or filariasis.[1] Encysted hydrocele of the cord remains asymptomatic or is detected incidentally during evaluation of other disease.[2] Rarely hydrocele of pancreatic origin has been reported to occur.[3] This article is a detailed report of a recent Ayurvedic medicinal management of Encysted hydrocele.

\section{Case History}

The parents of 3 year old boy found swelling in the child's right groin. He had no history of vomiting or constipation. The patient was born by normal vaginal delivery. There was no important past medical, surgical, or family history. On examination, the patient's abdomen was soft, non-tender, and non-distended, and there were normal active bowel sounds. A soft swelling was palpated in the right inguinal canal. The testes were descended bilaterally and were non-tender to palpation.

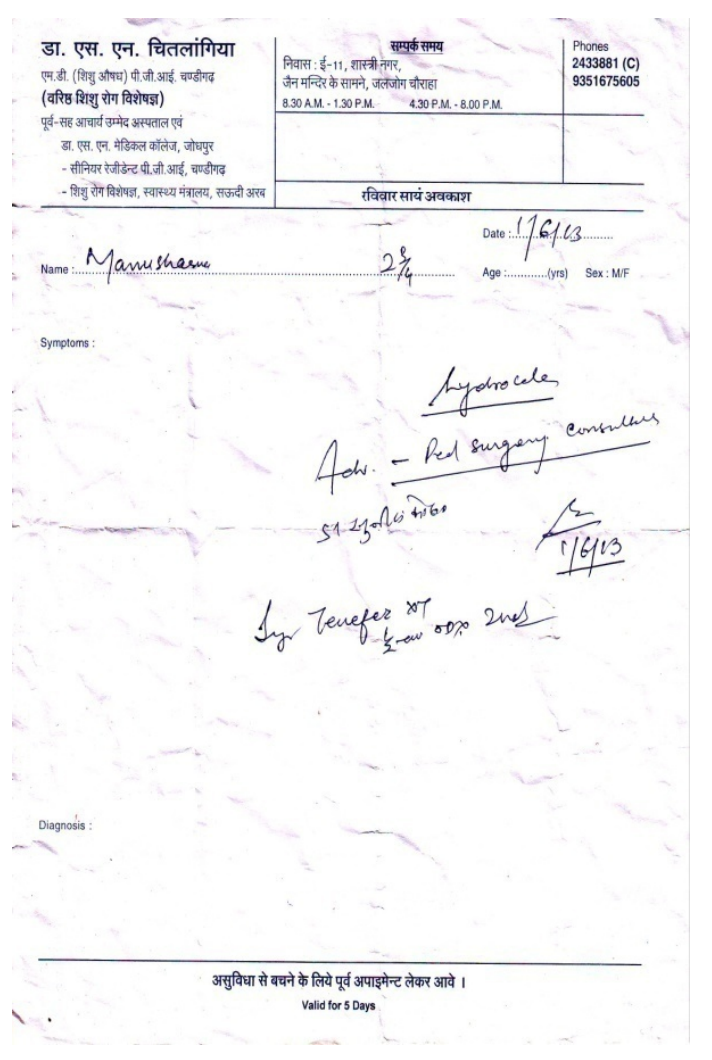

Figure 1

He had been examined first by Dr. S.N. Chitalangia, Ex Professor, Department of Pediatrics, Dr S N Medical College, Jodhpur, on $1^{\text {st }}$ June 2013, who has referred patient to the pediatrics surgeon. (Fig-1) The parents of child has discussed problem with pediatrics surgeon Dr Sunil Kothari, HoD, Department of Pediatrics Surgery at Dr S N Medical 
College, Jodhpur, on $1^{\text {st }}$ June 2013, for obtaining final opinion. He has advised to follow the USG of whole abdomen and Scrotum (Fig. - 2). It was re-confirmed. Parents have consulted with the authors on $6^{\text {th }}$ June 2013, for opting an Ayurveda medicinal management to avoid surgery.

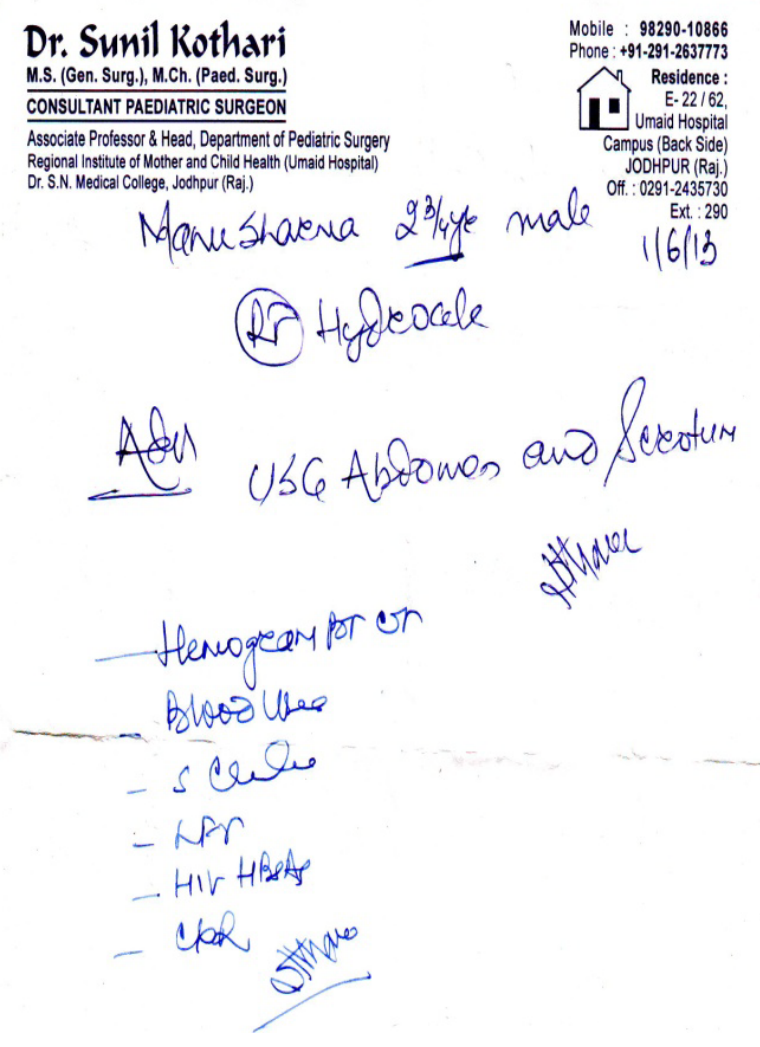

Figure 2

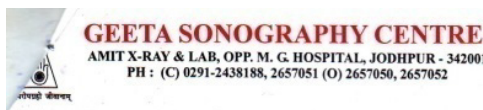
Dr. Shyam Batra, MD
Dr. Sanjay Khemchandani, MD, DNB
Dr. Amit Jain, MD T.RAY \& LAB, OPP. M. G HOSPITAL, JODHPUR - 34200
: (C) 0291-2438188, 2657051 (O) 2657050, 2657052

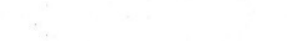

$\begin{array}{ll}\text { Name: Mr. Manu Sharma } & \text { Age: } 39 \text { yrs/male R.no: } 385 \\ \text { Ref by: Dr. Sunil Kothari } & \text { Date: } 02 / 06 / 2013\end{array}$

Sonography of Scrotum

Right Testis:

Right testis : $13 \times 08 \times 08 \mathrm{~mm}$

Right testes is normal in size and demonstrates normal parenchymal echotexture. Right epididymus are normal in size and demonstrates normal echogenicity. Septated cystic lesion measuring $51 \times 23 \times 26 \mathrm{~mm}$ is seen in right inguino-scrotal region,
displacing the right testis inferiorly.

Left Testis:

Lt. Testis : $16 \quad$ x $07 \times 10 \mathrm{~mm}$

Left testes is normal in size and demonstrates normal parenchymal echotexture.

Left epididymus are normal in size and demonstrates normal echogenicity.

Impression: Sonography findings are suggestive of :-

-Encysted hydrocele of right cord.

Suggested clinical correlation and further evaluation

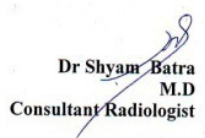

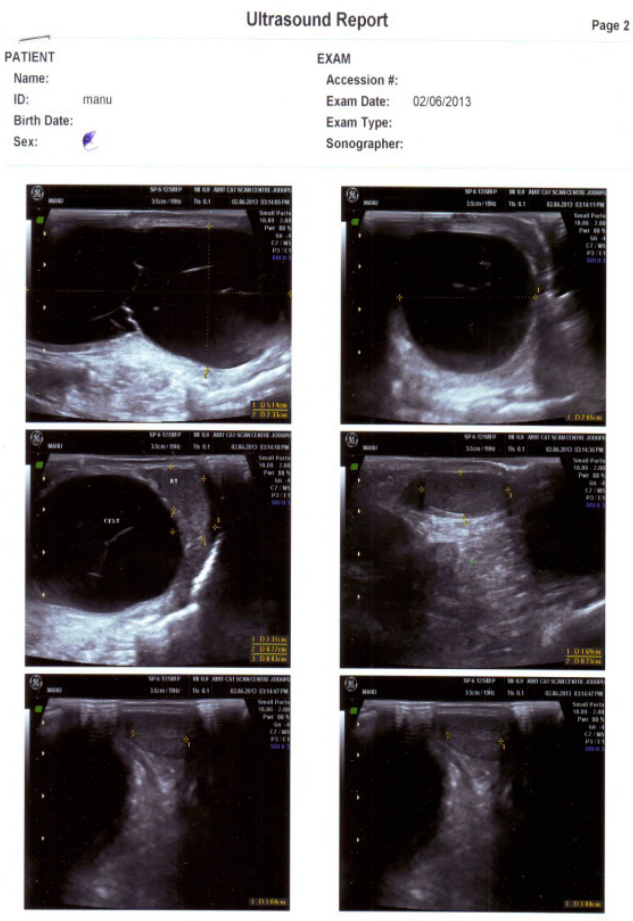

Figure 3

The case was taken up and reconfirmation of diagnosis was done through repeated USG. (Fig-3)The same diagnosis was re-confirmed. Treatment / Management were commenced on $6^{\text {th }}$ June 2013. A do \& don't guidelines was issued to parents. Parents were advised to follow the management, strictly.

Treatment:- The following treatment was prescribed:-

1. Sy. Septalin (Himalaya Drug) 2 x 3

2. Tab. Kanchanar Guggulu (Krishnagopal Kaleda) $1 / 3$ $\mathrm{x} 1 / 3 \times 1 / 3$

3. Pill. Vriddhi Badhika Vati. (Krishnagopal Kaleda) $1 / 2$ $\mathrm{x} 2$

4. Sy Tuff -1 TSF x 2 (Utkarsha Healthcare)

5. Sy Amyron (Amil Pharma) 1 TSF x 2

Follow Up: Treatment was commenced on $6^{\text {th }}$ June 2013. The case was followed up after every 10 days. Patient was brought on $16^{\text {th }}$ June 2013 for first follow up. Same treatment was continued. On $26^{\text {th }}$ June 2013 the patient was brought again.

Examination of patient shown that the size and swelling of Rt testicle was reduced significantly and returned to normal size. Same treatment was repeated. Patient was brought again on $14^{\text {th }}$ July 2013 . It has been observed that markedly improvement in the size and enlargement of the (Rt )Right testicle. Hence, it is advised to go for Ultra Sono Graphy (USG). (Fig-4)

\section{Results}

On $14^{\text {th }}$ July 2013 the patient was advised for USG of abdomen and scrotum for the confirmation of reduction in 
size. Report was received on 21th July 2013.

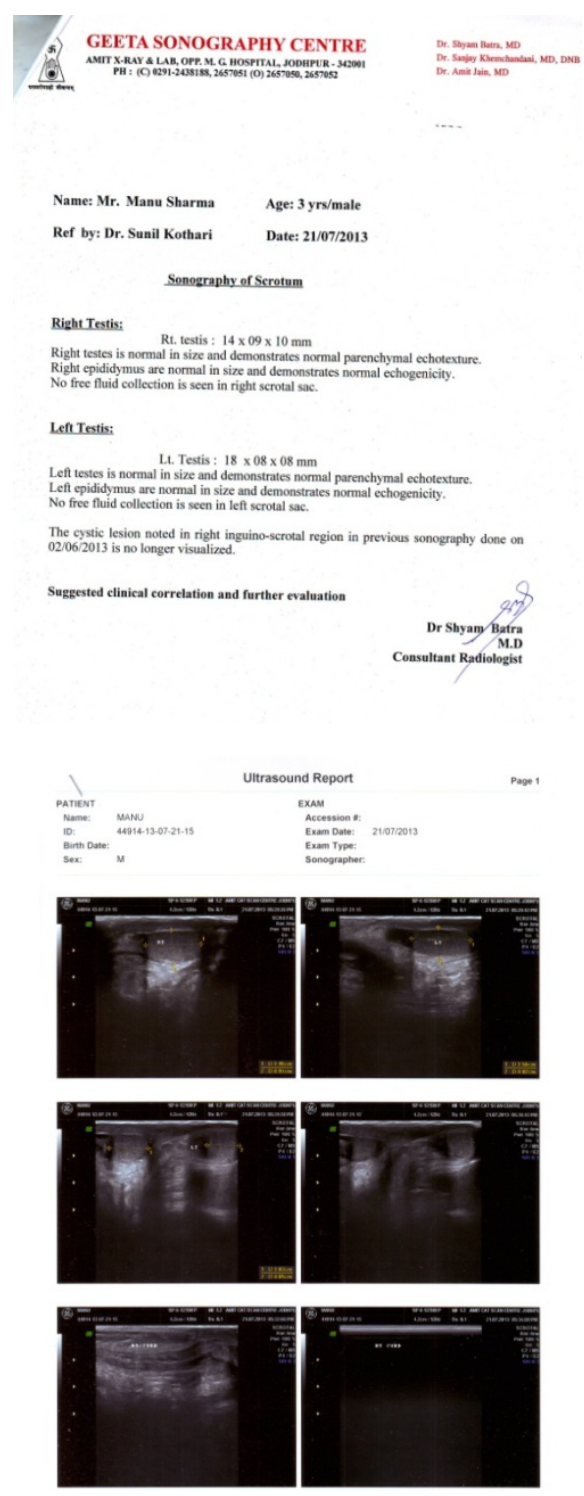

Figure 4. "The USG report refers that the size of Rt testis has reduced up to $14 \times 09 \times 10 \mathrm{~mm}$. Now the Rt testis was in normal in size and demonstrates normal parenchyma echotexture. Right epididymus are normal in size and demonstrates normal echo-genecity. No free fluid collection is seen in right scrotal sac. The cystic lesion noted in right ingunio-scrotal region in previous sonography done on $2^{\text {nd }}$ June 2013 is no longer visualized.

\section{Discussion}

During fetal development in the male, the testicle descends through the inguinal canal into the scrotum pulling along a sac-like extension of the peritoneum. By the first year of life, this extension condenses into a fibrous cord - the processus vaginalis, preventing the communication of peritoneal cavity with the scrotum. A thin membrane of this original extension remains surrounding the testicle which is named the tunica vaginalis. If this extension of peritoneum fails to close, based on the size of the defect, fluid or abdominal contents may enter the inguinal canal, resulting in a hydrocele or hernia. Congenital hernia or hydrocele, though more common in males, is rarely seen in females. In the female fetal development, round ligament of the uterus descends into the inguinal canal to the labium major. [4]

The main pathological conditions manifesting as masses in the groin fall into five major groups: congenital abnormalities, non-congenital hernias, vascular conditions, infectious or inflammatory processes, and neoplasms.[5]

Inflammatory swellings of the groin are common, and the changes are often attributed to infection and are often inflammatory swellings secondary to groin hernia.[6]However, painful spermatic encysted hydrocele presenting as a groin swelling is rare. Diagnosis is clinicaly essential but where doubt exists, scrotal ultrasound can be used to differentiate it from other scrotal lesions. Diagnosis can also be confirmed by computed tomography scan or intraoperatively. Spermatic cord hydrocele is effectively diagnosed by ultrasonography based on its specific location and shape. Ultrasonography is useful to exclude hernia, enlargement of the lymph node, or other solid masses.[7]

\section{Conclusion}

Encysted hydrocele in a child is common, now days. First choice of treatment is the surgery only. But, Ayurveda medicinal Management has shown a remarkable recovery. .It may open a new path to the clinicians and researchers for finding the medicinal option for the treatment of Encysted hydrocele in child. Collectively, it can be concluded that the Ayurveda management may help to overcome on this issue.

\section{Acknowledgement}

The authors acknowledge the thanks to Prof. Chakrapany Sharma, Ph. D., HoD, Depaetment of Dravyaguna Vigyan, Dr S R Rajasthan Ayurveda University, Jodhpur for contributing valuable suggestions.

\section{REFERENCES}

[1] Ku HJ, Kim ME, Lee NK, Park YH. The excisional, placation and internal drainage techniques: a comparison of the results for idiopathic hydrocele. BJU Int. 2001;87:82-84.

[2] Busigo J. P, Eftekharif F, Hendell H .Encysted Spermatic Cord Hydroceles : A Report of Three Cases in Adults and a Review of the Literature. Acta Radiologica. 2007; 48:1138-1142.

[3] Delamarre J, Descombes P, Grillot G, Deschepper B, Deramond H. Hydrocele of pancreatic origin. X-ray computed tomographic study of an intrascrotal collection in an acute outbreak of chronic pancreatitis. J Radiol. 1988;69:689-90. 
[4] Ortenberg J, Collins S, Roth CC. Pediatric Hydrocele and Hernia Surgery. [Last Updated on 2009 Sep 21]. Available from:

http://emedicine.medscape.com/article/1015147-overview , retrieved on 14th July 2013.

[5] Shadbolt CL, Heinze SBJ, Dietrich RB. Imaging of Groin Masses: inguinal anatomy and pathologic conditions revisited.
RadioGraphics. 2001;21:s261-71.

[6] Maheswaran P, Stephen D. A rare presentation of appendicitis as groin swelling: a case report. Cases J. 2009; 2 : 53.

[7] Han BH, Cho JY, Cho BJ, Ki WW Hydrocele of the Spermatic Cord: Ultrasonograhic Findings. J Korean Soc Med Ultrasound. $2002 ; 21: 129-133$ 